\title{
10 beliefs about computing: Contrary Evidence from a Study of Mobile Computing Use among Criminal Justice Personnel
}

\author{
Andrea Tapia \\ Steve Sawyer \\ School of Information Sciences and Technology \\ Pennsylvania State University \\ University Park, PA U.S.A.
}

\begin{abstract}
In this paper, we explore how technological determinism can act as a belief system. To do so, we draw on a multi-organization field trial of uses of mobile computing by criminal justice personnel. Our findings make clear that mobile computing does not yet meet operational needs. In high contrast, we find that the belief these mobile computing technologies will solve the preponderance of organizational, informational, and communication problems that beset contemporary criminal justice efforts is unchanged by the shortcomings of the current environment. While the devices, applications, and telecommunications network never worked as intended or expected, their introduction was met with acceptance, enthusiasm, and the deterministic belief that they would make work better. We go beyond the common explanation of learning from a field trial and explore the contradictions inherent to the findings through the lens of technological determinism. In doing this, we highlight several implications that deterministic beliefs have regarding organizational value of field trials and research conceptions regarding the introduction of new computing technologies.
\end{abstract}

\section{INTRODUCTION}

Through this paper we make two contributions. We provide empirical evidence on workers' experiences with increased levels of connectivity while mobile. This serves as a means of gaining insight into what mobile computing might mean in organizational 
settings. Second, we examine the implications of technological determinism relative to introducing new computing by drawing on our empirical evidence.

These two contributions arise from a multi-organizational field trial of mobile workers in criminal justice organizations. We found that the mobile devices and wireless access never were successfully incorporated into the already complex network of information and communication technologies (ICT) used and often worn by each participating officer. This, however, did not diminish the belief that such mobile technologies will solve the preponderance of organizational, informational., and communication problems that plague criminal justice in the United States (e.g., Rudman et al. 2003).

In studying mobile access to computing resources in criminal justice, we note that at present most criminal justice personnel are unable to access valuable resources when mobile. Instead, they have learned to rely on the limited resources they bring with them and that dispatchers and dispatch centers can provide for most of their information needs. With the increased bandwidth available via third-generation ( $3 \mathrm{G}$ ) wireless networks, however, it becomes theoretically possible to deliver data to criminal justice personnel wherever they are. This change with respect to access by users has potentially profound implications for organizational strategies in this space and can serve as a lens into the value and opportunities for ubiquitous access to information in other industries and other organizational sectors.

This paper continues in four parts. First, we provide a short overview of the institutional (criminal justice) and computing elements that together serve as the focus of this field trial. Second, we review the conceptual basis for our research, outline our research design, and explain our data collection methods and analysis. Third, we present our findings. In the fourth section, we build on concepts of technological determinism and cognitive dissonance to explore how the evidence from the trial contradicts the beliefs about the ICT held by the participants.

\section{CRIMINAL JUSTICE, COMPUTING AND MOBILITY}

There are at least three reasons why criminal justice is an appropriate domain for studying mobile work. First, the work of criminal justice officers is (and has been) highly mobile, knowledge intensive, and pervasive. Second, recently there is great interest in using ICT to better support these workers' information needs. Third, criminal justice has long been a focus of academic study and that provides us with an extensive reference literature (see Klockars and Mastrofski 1991; Manning 1977, 2003; Nunn 2001).

Current research findings provide contrary views regarding adoption and use of ICT in criminal justice (Allen and Wilson 2004; Brown 2001; Lin et al. 2004; Nabbubg 29931 Pica and Kakihara 2003). Some departments have well-structured programs to bring computing together with their work practices. These departments either select offthe-shelf systems or have vendors develop systems suitable to fulfill specified needs or roles. This stretches into wireless technologies as well (NASCIO 2003; Taylor et al. 
1998). Evidence exists that the adoption of new ICT and uses of mobile technologies (beyond the nearly omnipresent radio communications suite in most cars and with most police officers in the United States) is accelerating in the United States (Nunn 2001). Partly this is in response to the country's increased attention to homeland security (Rudman et al. 2003); although efforts to improve policing through advanced computing predate this current attention (Northrup et al. 1995).

For the purposes of the trial on which we report, the $3 \mathrm{G}$ network is one of three elements of a technical infrastructure that underlies an integrated criminal justice information system. Beyond the mobile data network access, the technical infrastructure includes access to and use of Pennsylvania's justice network (JNET) ${ }^{1}$ via mobile devices that the users have with them. This focal application was JNET, a secure Web-based portal connecting authorized users to a set of 23 federated criminal justice and law enforcement databases via a query-based interface. The JNET architecture is characterized by three elements. First, it acts as a portal to the criminal-justice-related databases of the Commonwealth of Pennsylvania (and the U.S. Federal government). Second, JNET is a secure system. Users are carefully vetted before they get access, their use is tied to specific roles, and these roles grant them varying levels of access to the range of data available. Third, JNET provides electronic messaging, e-mail and reporting functions. JNET has been operational since early 2000 and it supports thousands of queries each month (and use has grown by nearly 10 percent per month since inception). ${ }^{2}$

The third part of the technical infrastructure is the device being used to provide mobile access to JNET (and to the Internet more broadly). We studied both laptop and personal digital assistant (PDA) technology. These must have a special $3 \mathrm{G}$ modem card. Most police cruisers have an integrated laptop $\mathrm{PC}$, making this seemingly a trivial effort (put in the wireless modem card, load on the security software, and use a browser). However, there were a number of operational and legal issues that made this a nontrivial effort. For example, many of the laptops are not equipped with space to load the modem card. Battery draw on police cruisers is substantial, and this further limits laptop use (and the $3 \mathrm{G}$ modem cards draw substantial power to run the antenna and maintain connectivity). Moreover, some cruiser's laptops have other software whose security and operational or licensing requirements preclud additional applications from being added.

For officers not in a cruiser, the mobile device must be carried on their person. Again, this is not a trivial effort considering that almost every square inch of the average police person's body is covered by some piece of gear. Moreover, the combination of current equipment (including communications, weapons, body armor, etc.) weighs nearly 25 pounds. This means that adding a mobile device is a significant decision.

${ }^{1}$ For more information about JNET, see www.pajnet.state.pa.us.

${ }^{2}$ JNET 2004 usage statistics, available online at http://www.pajnet.state.pa.us/pajnet/ site/default.asp. JNET is one of the earliest and most visible examples of a small and growing group of integrated criminal justice information systems that are a focus of homeland security efforts in the United States. Others include the Capital Area Wireless Integrated Network (CAPWIN, see www.capwin.org), the automated regional justice administration system (ARJIS, see www.arjis.org) and a fast-growing number of municipal efforts such as systems in Montgomery County, Maryland, and Los Angeles County, Califormia. 


\section{FIELD TRIAL DESIGN, DATA COLLECTION, AND ANALYSIS}

The research reported on here is guided by the belief that field trials of mobility provide insights into how work will be organized, governed, and supported by ubiquitous and information technology-intensive infrastructures (e.g., Green 2002; Lyytinen and Yoo 2002a). ${ }^{3}$ Heeding Orlikowski and Iacono's (2001) call to better theorize the IT artifact, we conceptualize mobile access to JNET as a socio-technical ensemble. This view helps to highlight interdependencies among people (workers and managers) who use the ICT, the organizational rules and roles that guide both people's actions and the ICT's uses, and the situated nature of these relationships (that occur in specific times and places, in specific events).

A second source of guidance in designing the field trial comes from Jessup and Robey (2002), who suggest that studies of mobile computing in the workplace environment focus on individual, team and organizational levels of analysis. Lyytinen and Yoo (2002b) suggest an organizational perspective and within that focus on network externalities and coordination or control uses as drivers of these changes. Sawyer, et. al. (2003) suggest an institutional perspective and focus on identifying value and negotiating governance (control) as central issues.

The design of our field trial focused on collecting data at and across three levels of analysis. At the technical level, we focused on the $3 \mathrm{G}$ network's coverage, access, connectivity, and security, uses of applications (particularly JNET), and device operations. At the individual level, we focused on the adoption and uses of the devices and JNET relative to officers' work processes and relevant tasks changed. At the organizational level, ${ }^{4}$ we focused on structural and governance changes relative to the tasks and business processes such as the role of dispatch, operational control, and interorganizational interactions and, in doing so, leverage the extensive knowledge of policing and partially control for institutional factors.

The field trial was designed as a structured intervention: mobile workers were provided with a mobile device and secure access to the public $3 \mathrm{G}$ network. For pragmatic reasons, this was done in two phases. The first phase lasted 3 months, included 5 participants and focused on laptop usage. The second phase began directly after the completion of the first phase, involved 13 participants, lasted 3 months, and focused on personal digital assistant (PDA) usage. Participants in both trials were police

${ }^{3}$ Lyytinen and Yoo (2002b) note the terms mobile, ubiquitous, and pervasive are too often used interchangeably with respect to computing. They argue that mobility refers to devices that are mobile, but not embedded. Pervasive devices are embedded, but not always mobile. Ubiquitous devices are both mobile and embedded. A ubiquitous device is commonplace, portable, and nearly invisible. A pervasive device is one that is commonplace, but not very portable. In the case of the field trial we report on here, officers currently have mobile devices (such as radios and in-cruiser computers) and the interest was in increasing their embeddedness. To do this, we focused on leveraging the pervasive value of JNET by making it accessible from mobile computers.

${ }^{4}$ The organizational level of analysis is drawn from the criminal justice institutional field. 
and other criminal justice officers from three organizations (one county-level and two local-level) located within one U.S. county.

We used seven forms of data collection. First, we did interviews of all users at the beginning and end of each trial period. Second, we led focus groups of users following the trials. These were voluntary, and only two participants did not participate (for schedule reasons). Third, all users completed a 1-week time diary of work behavior during the field trial. Fourth, members of the research team did ride-alongs. Fifth, we gathered documents during all interviews, observations, and visits (and did extensive Web and library research to support the field work). Sixth, we engaged in informal weekly interactions (via phone, e-mail, and in person). Finally, we gathered data about laptop uses, wireless data transmission, and JNET usage via unobtrusive means (such browser logs, server logs, and telecom activity logs). Data from the first six sources were either transcribed into digital format or collected at the source in digital format. Data from the usage logs came in digital format.

\section{FINDINGS}

In the first part of this section, we summarize six findings drawn from the data on the field trial (see Table 1).

Table 1. Findings from the Field Trial of $3 \mathrm{G}$ Mobile Access to JNET

\begin{tabular}{|c|c|}
\hline Level & Finding \\
\hline Technical & $\begin{array}{l}\text { 1. Current ICT infrastructure is unable to support production } \\
\text { needs at this time }\end{array}$ \\
\hline Technical & 2. Users used their mobile devices other than expected \\
\hline Individual & $\begin{array}{l}\text { 3. Value of mobile access to criminal justice work is } \\
\text { certainty of access }\end{array}$ \\
\hline Individual & $\begin{array}{l}\text { 4. Officers need access for smaller percentage of their work } \\
\text { time than expected }\end{array}$ \\
\hline Organizational & $\begin{array}{l}\text { 5. Mobile access does not replace the need for central } \\
\text { coordination or dispatch. }\end{array}$ \\
\hline Cross-level & $\begin{array}{l}\text { 6. There is minimal support for a complex and often chaotic } \\
\text { ICT infrastructure }\end{array}$ \\
\hline
\end{tabular}




\subsection{Current ICT Infrastructure Is Unable to Support Production Needs at this Time}

The officer in this trial had to grapple with the constraints of secure access, limited coverage, and unstable access to the $3 \mathrm{G}$ wireless network. For example, the "always on" possibility that $3 \mathrm{G}$ networks provide (due to their use of packet-based, Internet protocol, spread-spectrum transmission) was never realized because of the mandated constraints of JNET application security. The (required) two-factor login was both difficult to follow and time-consuming to initiate. The virtual private network (VPN) would shut down if the bandwidth fell below a certain point (and this meant users had to re-authenticate). Moreover, JNET requires periodic validation of users and will shut down if this is not done. Trial participants were highly conscious of security of information and they valued the steps taken by JNET to keep information secure during the field trial even though it added several steps to the logon process.

A common problem with this trial was the lack of $3 \mathrm{G}$ coverage within the rural areas that the trial covered. Coverage maps provided by the vendor indicated more than 70 percent of the area was covered. In practice, coverage was far less than expected. Furthermore, the life of the PDA battery was not sufficient to maintain connection to the $3 \mathrm{G}$ network over long periods and this led trial participants to stop using their PDAs for mobile access.

\subsection{Users Used Their Mobile Devices Other than Expected}

While officers did not use the wireless network to the degree expected, they made great use of their mobile devices. Officers began to use the PDAs for scheduling, contacts, note-taking, and a host of other tasks. As Manning (2003) notes, criminal justice officers are willing to take on new tools and eager to adapt them to their needs. But criminal justice officers are not willing to compromise their (or anyone else's) safety if the device or application does not work. Further, they are unwilling to tinker with applications that are used infrequently. We note that JNET applications, which are very useful for deskbound workers, are neither fast enough nor focused on the needs of mobile workers, making it difficult for them to use by themselves in active incidents. The officers did not stop using JNET; they just stopped accessing JNET via mobile devices.

\subsection{Value of Mobile Access to Criminal Justice Work Is Certainty of Access}

The measure of value is not volume or frequency of use for these officers. Their measure is certainty of access when needed. In the same way that a gun is important to have (even if 97 percent of all officers never fire their side-arm as part of their job), access to JNET (and more specifically photos) is highly valued (officers must be certain that it will work when they "draw it from their holster"). The value is driven in great 
part by the reliability of their mobile connectivity (otherwise it is just as likely that the officer will return to their fixed office to access this data). These officers' work worlds revolve around geographies of local communities, and they live balancing routine with emergency. A quiet drive around their beat can be shattered by a horrific traffic accident or domestic disturbance, and this puts their life at risk. In these moments of crisis, the officer cannot doubt that the weapon will function as expected. In that same moment, even if the mobile technology has not been used for weeks, the offier must be certain that device will work on cue and as expected. We learned that connection reliability and incident management is more important to these officers than are data download speed.

\subsection{Officers Need Access for a Smaller Percentage of Their Work Time than Expected}

Trial participants are not always engaged in tasks that require mobile access to JNET. The value of mobile access seems to be tied to particular aspects of their work. Mobile access and JNET use seems important to only certain tasks and events in the work of our participants. For example, in the 8-hour shifts we observed through ridealongs, officers typically were engaged in information seeking tasks for less then 15 percent of the total shift time. Self-reported time diaries corroborate that informationseeking activities are a small but very critical aspect of the police officer's work.

\subsection{Mobile Access Does Not Replace the Need for Central Coordination or Dispatch}

Wireless communication devices may have a role in facilitating communications between criminal justice personnel, but in this case they do not reduce the number of people involved in the process of completing any task, change the role that any person currently plays, nor reduce the number of steps in any process. The real implication for wireless technology is using the current people and processes but allowing information to flow more quickly from repositories to people, and from person to person, at very important critical moments. Mobile JNET is not cost saving-but it is likely to be life saving.

\subsection{There Is Minimal Support for a Complex and Often Chaotic ICT Infrastructure}

Criminal justice organizations have limited ICT support and diverse ICT infrastructures. The officers in our trial relied chiefly on themselves and on each other to learn to use and troubleshoot the devices. This seems to be the way they have learned and supported all of their ICT. Each of the three units participating in the trial had different IT infrastructures and often these were supported through a of variety contracts with different third party vendors. 


\section{IMPLICATIONS AND ISSUES WITH THE MYTHOLOGY OF UBIQUITY}

In the last week of the field trial, no officers attempted to log on from a mobile device to the $3 \mathrm{G}$ network or to access JNET from a mobile device. In our post-trial focus groups and debriefing, officers reported that they were pleased to have participated. Many spoke highly of their experiences with the trial sponsors and research staff, praised the idea, the potential, and the value of JNET. This exuberance seemed an odd contrast to the record of use. Moreover, three of the officers rarely, if ever, used their mobile access (once or perhaps twice a shift). Three others used it for several hours a shift at their most engaged point. But even the most aggressive users had come to closure on the field trial before the trial had come to an end.

How can we reconcile their behaviors to these espoused beliefs? Trial participants welcomed the mobile devices and advanced ICT in general, but they did not use the devices or service to any great extent. Trial participants are hopeful about the roles that mobile devices and wireless access can play in making their work life safer and also better enable them to perform their duties, but they are critical of the operation of these devices and the services. The officers in our trial took a long-term perspective: they were willing to wait until something is proven to work before taking it on as part of their daily routine. Despite the connection, battery, and logon problems, the officers continued to see the potential for these mobile devices as creating greater efficiency, better communication, and added safety.

In this final section, of the paper we reflect on the meanings and implications of these findings. In Table 2 we illustrate that in several areas the officers held to a set of beliefs concerning this new ICT despite evidence contrary to what they expected. For example, officers believed that the mobile access to JNET via $3 \mathrm{G}$ wireless networks would offer increased efficiency, would make their jobs easier, would reduce the workload of the dispatch personnel, and would increase criminal justice effectiveness in general. However, the mobile devices never functioned as promised and there was never any evidence they would. Even at the end the trial period, officers held fast to the belief that the ICT would solve problems. This claim was even more ironic and more powerful because each of the participating officers was able to relate tales of failed computing interventions from previous experiences. Several officers discussed failed report-writing software, poor in-vehicle devices, limited technical support, and other failures in policing.

Through this trial, we expected that the integration of mobile computing would be relatively seamless. Officers were using laptops in their cars and cruisers. However, we found that the officers made use of a very small range of laptop functionality and onboard applications (relying primarily on voice interactions with central dispatch instead).

We anticipated that the mobile devices and $3 \mathrm{G}$ network would function with little support needed by us. We found that the operational environment was much more demanding, the officers were much harder on the equipment, and the coverage far less than we expected. So, our expectation that there would be little or no need for organizational and technical support was woefully optimistic. In phase two of the trial, we added technical support (essentially 1.5 hours per person per week) and it was not 
Table 2. Myths of Ubiquity

\begin{tabular}{|l|l|l|}
\hline & \multicolumn{1}{|c|}{ Myth } & \multicolumn{1}{|c|}{ Evidence } \\
\hline Integration of new devices & Seamless & Poor \\
\hline Function of devices & Perfectly & Poorly \\
\hline $\begin{array}{l}\text { Function of third generation } \\
\text { wireless network }\end{array}$ & Well & Poorly \\
\hline $\begin{array}{l}\text { Need for organizational and } \\
\text { technical support }\end{array}$ & Little need & Highly needed \\
\hline Role of dispatch & Dispatch less central & No change \\
\hline Criminal justice & $\begin{array}{l}\text { Catch more "bad guys" } \\
\text { and close more cases } \\
\text { (efficient and effective) }\end{array}$ & No change \\
\hline Instances used & High/often/regularly & Rarely \\
\hline
\end{tabular}

enough. We learned that there is little ongoing organizational-level technical support for the small police departments in our field trial. This meant that for us to get our applications and devices operational, we often had to first resolve the existing backlog of technical issues (with e-mail, applications, access, and hardware breakdowns). This, in turn, was a complicated effort because it required us to negotiate across a host of outsourced IT units and internal IT people working (with or) for a range of state, county, and local governments.

We expected that the use of mobile $3 \mathrm{G}$ access to JNET would alter the ways in which officers interacted with dispatch (less reliance) and more interaction with other units and personnel (because it was easier to share information). We saw no change across the 7 months of our study. Dispatch remained the undisputed center of interorganizational interaction and there were no discernable changes in the number or structure of officer-to-officer interactions.

One aspect of the study was to focus on the officer's efficiency (measured in terms of incidents and cases that were closed). We expected that greater access to information would improve efficiency. However, this was not supported. Further, we expected that use of the mobile access to JNET would become regular, common, and often. As we noted above, use was sporadic, tied to tasks that account for about 15 percent of the officer's field work, and inhibited by a host of recurring operational shortcomings.

\subsection{Technical Determinism and Mythic Conceptualizations}

One explanation for these contradictory findings is technological determinism. It seems that the ICT ensemble represented here by $3 \mathrm{G}$ wireless-enabled mobile devices accessing JNET is viewed by organizational members through the lens of technological 
determinism. ${ }^{5}$ Organizational members believed that mobile access to JNET would improve their work, their organizations, and their lives. Participants viewed the results with the acceptance that current problems are a result of a temporary setback (in the case of negative findings), enthusiasm (in the case of positive findings), and the deterministic belief (seemingly independent of the findings) that they would eliminate the problems uncovered here in future trials and deployments.

This deterministic perspective stands in contrast to the evidence drawn from the trial. This contrast leads us to consider the concept of technological determinism as a belief (and not solely a theory). Technological determinism is a philosophical stance about both technology and the human condition. Technological determinists (Adorno and Horkheimer 1944; Ellul 1964; Ferkiss 1974; Heidegger 1977; Marcuse 1941) argue that technology itself is capable of restructuring the social world in its own image. These determinists tend to have polarized responses to technology in that they find technology's effect as either socially liberating or socially oppressive. Technological change is viewed as both a necessary and a sufficient condition determining all other social change. (McGinn 1991, p. 74). In organizational terms, the social system of an organization is compelled to mold itself to the technology. In other words, changes in the technical system of an organization translate directly into changes in organizational structure or functioning (Adler 1987; Khandwalla 1974; Thompson 1967; Woodward 1965).

Winner (1986), in his famous work "Do Artifacts Have Politics?," rejected the technological determinist's framework and claimed that technologies should be judged not only for their utilitarian effects on organizational efficiency, but perhaps more importantly for the symbolic ways in which they embody power and authority. Thomas argued in his work, What Machines Can't Do, that social and technical systems are jointly responsible for organizational structuring and change and that the relationships among technology and organization are mediated by the exercise of power (1994, p. 5).

This development in the social study of technology opened the doors to the study of technology in a cultural light. Several authors have begun to discuss the emotional framing of technology by modern Western society (Alexander 1992; Davis 1998; Grosso 1995; Postman 1992; Rozak 1994; Tenner 1996). They propose that through the interplay between technology and culture, technology is interpreted and framed as either the savior or the destroyer of humanity.

Alexander (1992, p. 40) goes further, arguing that as an object is made sacred by being sealed off from the profane world, gaining access to its power becomes a problem in itself. Priests emerge as intermediaries between the divinity (computer) and the laity. A technological expert class is created. In contemporary information systems literature, Kaarst-Brown and Robey (1999) build on this mysticism and the creation of a technological expert class. They draw on the metaphor of magic using dragons and wizards to produce cultural insights for IT management. In this paper, we focus on myth as an imaginative story using powerful symbols and colorful images to help people

${ }^{5}$ For this study, this view is essentially positive, although this does not need to be the case. For example, Kling (1980) identifies that both utopian and dystopian views of technology are powerful lenses that provide, at best, a partial understanding of the roles of computing in organizations. 
understand concepts either too complicated or too difficult to express in words. Myths may have originated in truth or may continue to hold a kernel of truth as they are told, but what most clearly defines them are their exaggeration, fanciful elaboration, and interpretation of that kernel. We suggest that modern myths are passed from person to person through the telling of stories through a variety of media. These stories serve to build aspects of our wider American culture, as well as smaller, organizational cultures, and may prompt individuals to behave in new, culturally specific ways.

Seen this way, technological determinism is mythic. This elevation of a relatively simple theory to become a myth is both subtle and profound. In mythic terms, the value of ICTs is framed as a (if not the) means forward, out of the crises and complexities of contemporary policing. Manning (2003) grapples with this, noting on one hand the pragmatic pro-orientation toward ICT: "Each information technology at first competes for space, time and legitimacy with other known means and is judged in policing by somewhat changing pragmatic, often nontechnical values"' (p. 133). In contrast, though: "There is little evidence that thirty years of funding technological innovations has produced much change in police practice or effectiveness" (p. 134).

At the trial's end, then, do we interpret the limited success as a basis for the next trial's grand improvements, or do we confront the starkness that increasingly ubiquitous computing (at least in criminal justice) is not likely to bring significant value? If the former is true, then our first six findings are where the value lies. If the latter is true, what evidence is required to change one's beliefs from focusing on the first? What happens if the next trial also fails?

\subsection{Cognitive Dissonance in Reconciling Evidence and Belief}

How can we reconcile the evidence with the belief? Festinger et al. (1956) argue that when an individual holds a strong conviction and is faced with unequivocal and undeniable evidence, their belief was wrong: "The individual will frequently emerge, not only unshaken, but even more convinced of the truth of his beliefs than ever before. Indeed, he may even show a new fervor about convincing and converting other people to his view" (p. 3). For Festinger et al., the moment of realization that a deeply held conviction was wrong creates a sense of cognitive dissonance in the mind of the believer.

All of the officers in this study experienced this form of cognitive dissonance in that their beliefs of the potential of mobile access to JNET to change their lives were challenged. It seems, though, that they emerged unscathed, holding fast to their previously strong beliefs of technological determinism. ${ }^{6}$ Their dissonance was mediated by the fact that in the case of all myths, there usually is a kernel of truth. Most officers

${ }^{6}$ It may be that readers of this paper struggle with this also. Is this paper reporting on a "failed" field trial or is it reporting on a failed premise? It is easier to respond to the former concern: the six findings provide substantial guidance on what to do next, and that is clearly not a sign of a failure. 
knew of an instance, had heard a rumor, or had read an article that declared the success of an implementation of a technology into policing that had met with unprecedented workplace change, efficiency and success. This one instance was strong enough that it provided a base on which these officers could anchor their beliefs concerning the power and potential of technology. Despite the failure of several trials and several devices in their own organization, they believed that somewhere out there, something was working well for someone.

These officers dealt with their cognitive dissonance by making claims that the timing was not quite right, that if the wireless providers were given a bit more time to improve their rural networks, the coverage would be improved and the devices would transform into the desired object. They also claimed that perhaps the laptop or PDA was not "the one" device that would transform their jobs, that device was coming.

\subsection{The Blinding Power of Technological Determinism}

Thinking about mobility leads us to more closely examine the deterministic theme running through these organizations concerning ICT. There are at least three pragmatic consequences that arise from (the seemingly unsupportable) confidence in the future values of ICT. First, that organizational decision-makers, users, and technology evaluators will likely continue to seek ICTs that will provide them the simple path forward. Second, these same people will have trouble making sense of evidence drawn from failed attempts to implement and use ICTs (since the direct effects model is unlikely to be empirically supported). The inability to understand this data is driven by the unsound basis of direct effects thinking, not by the measurements taken or instruments used to gather evidence (e.g., Sawyer et al. 2003). A third consequence is that the cognitive dissonance arising from the seemingly unsupportable confidence in technological determinism suggests that these officers are willing, if not eager, to take on additional trials. This further suggests that proactive systems design approaches are likely to lead to useful applications and, in doing so, the interactions are likely to reinforce the belief that mobile, ubiquitous computing is possible. This seemingly selfreplenishing reservoir of good will towards working toward a better technological infrastructure provides technology developers, scholars, and organizational leaders the opportunities to continue experimenting (and studying) new devices, access methods, and services. It is not clear to us what experiences with a trial might drain this reservoir.

Brooks (1987) noted, in the context of automating software development, that there is no silver bullet. No one seems to think there is a silver bullet for uses of ICT in criminal justice. It may be that they think the better response is to fire more bullets. If technological determinism is a belief -and not just a theory--then our analysis suggests that efforts such as the work being done in criminal justice to engage pervasive and ubiquitous computing may provide an empirical opportunity to understand the consequences.

\section{REFERENCES}

Adler, P. (Ed.). Technology and the Future of Work, New York: Oxford University Press, 1992. 
Adorno, T., and Horkheimer, M. "The Culture Industry: Enlightenment as Mass Deception," in Dialectic of Enlightenment, 1944.

Alexander, J. "The Promise of a Cultural Sociology: Technological Discourse and the Sacred and Profane Information Machine," in Theory of Culture, R. M. Smelser (Ed.), Berkeley, CA: University of California Press, 1992, pp. 293-323.

Allen, D., and Wilson, T. "Action, Interaction and the Role of Ambiguity in the Introduction of Mobile Information Systems in a UK Police Force," in Proceedings of the IFIP TC8 Working Conference on Mobile Information Systems, September 15-17, 2004, pp. 15-36.

Brooks, F. "No Silver Bullet: Essence and Accidents of Software Engineering," Computer (4:1), 1987, pp. 10-19.

Brown, M. "The Benefits and Costs of Information Technology Innovations: An Empirical Assessment of a Local Government Agency," Public Performance \& Management Review (24:4), 2001, pp. 351-366.

Davis, E. Techgnosis, New York: Random House, 1998.

Ellul, J. The Technological Society, New York: Alfred A. Knopf, 1965.

Ferkiss, V. Technological Man: The Myth and the Reality, New York: George Brazilier, 1969.

Festinger, L., Riecken, H., and Schachter, S. When Prophecy Fails, Minneapolis, MN: University of Minnesota Press, 1956.

Green, N. "On the Move: Technology, Mobility, and the Mediation of Social Time and Space," The Information Society (18:4), 2002, pp. 135-152.

Grosso, M. The Millennium Myth, Wheaton, IL: Theosophical Publishing Press, 1995.

Heidegger, M. The Question Concerning Technology, New York: Harper and Row, 1977.

Jessup, L., and Robey, D. "The Relevance of Social Issues in Ubiquitous Computing Environments," Communications of the ACM (45:12), 2002, pp. 88-91.

Kaarst-Brown, M. L., and Robey. D "More on Myth, Magic and Metaphor: Cultural Insights into the Management of Information Technology in Organizations," Information, Technology and People (12:2), 1999.

Khandwalla, P. N. "Mass Output Orientation of Operations Technology and Organizational Structure," Administrative Science Quarterly (19), 1974, pp. 144-156.

Kling, R. "Social Analysis of Computing: Theoretical Perspectives in Recent Empirical Research," ACM Computing Surveys (12:1), 1980, pp. 61-110.

Lin, C., Hu, P. J-H., and Chen, H. "Technology Implementation Management in Law Enforcement," Social Science Computer Review (22:1), 2004, pp. 24.

Lyytinen, K., and Yoo, Y. "Issues and Challenges in Ubiquitous Computing: Introduction," Communications of the $A C M(45: 1), 2002 \mathrm{a}, \mathrm{pp} .62-65$.

Lyytinen, K., and Yoo, Y. "The Next Wave of Nomadic Computing," Information Systems Research (13:4), 2002b, pp. 377-388.

Manning, P. Police Work: The Social Organization of Policing, Prospect Heights, IL: Waveland Publishing, 1977.

Manning, P. Policing Contingencies, Chicago: University of Chicago Press, 2003.

Marcuse, H. "Social Science Implications of Modern Technology," Studies in Philosophy and Social Sciences (9:3), 1941, p. 425

McGinn, R. Science, Technology and Society, Englewood Cliffs, NJ: Prentice Hall, 1941.

NASCIO. "Concept for Operations for Integrated Justice Information Sharing Version 1.0," National Association of State Chief Information Officers, July 2003 (available online at https://www.nascio.org/publications/index.cfm).

Northrup, A., Kraemer, K., and King, J. "Police Use and Computers," Journal of Criminal Justice (23:3), 1995, pp. 259-275.

Nunn, S. "Police Information Technology: Assessing the Effects of Computerization on Urban Police Functions," Public Administration Review (61:2), 2001, pp. 221-234.

Orlikowski, W., and Iacono, S. "Desperately Seeking the 'IT' in IT Research-A Call to Theorizing the IT Artifact," Information Systems Research (12:2), 2001, pp. 121-124. 
Pica, D., and Kakihara, M. "The Duality of Mobility: Designing Fluid Organizations through Stable Interaction," in Proceedings of the $11^{\text {th }}$ European Conference on Information Systems, C. Ciborra, R. Mercurio, M. DeMarco, and O. Hanseth, Naples, Italy, June 19-21, June 2003, pp. 259-275.

Postman, N. Technopoly, New York: Vintage Books, 1992.

Rozak, T. The Cult of Information, Berkley, CA: University of California Press, 1994.

Rudman, W., Clarke, R., and Metzel, J. "Emergency Responders: Drastically Underfunded, Dangerously Unprepared," Report of an Independent Task Force Sponsored by the Council on Foreign Relations, July 29, 2003 (available online at http://www.cfr.org/pdf/ Responders_TF.pdf).

Sawyer, S., Allen, J., and Lee, H. "Broadband and Mobile Opportunities: A Sociotechnical Perspective," Journal of Information Technology (18:2), 2003, pp. 31-50.

Taylor, M., Epper, R., and Tolman, T. Wireless Communications and Interoperability among State and Local Law Enforcement Agencies, Report 168945, National Criminal Justice Institute, Washington, DC, 1998.

Thompson, J. Organizations in Action, New York: McGraw-Hill, 1967.

Thomas, R. J. What Machines Can't Do, Los Angeles: University of California Press, 1994.

Winner, L. "Do Artifacts Have Politics?," The Whale and the Reactor: A Search for Limits in an Age of High Technology, Chicago: University of Chicago Press, 1986, pp. 19-39.

Woodward, J. Industrial Organizations: Theory and Practice, London: Oxford University Press, 1965.

\section{ABOUT THE AUTHORS}

Steve Sawyer is a founding member and associate professor at the Pennsylvania State University's School of Information Sciences and Technology. Steve holds affiliate appointments in Management and Organizations; Labor Studies and Industrial Relations; and the Science, Technology and Society. He does social and organizational informatics research with a particular focus on people working together using information and communication technologies. Steve can be reached at sawyer@ist.psu.edu.

Andrea Hoplight Tapia is an assistant professor of Information Sciences and Technology at the Pennsylvania State University. Prior to her arrival at Penn State, Andrea completed a National Science Foundation funded post-doctoral fellowship at the University of Arizona entitled "Universities in the Information Age." Her Ph.D. is in the area of Sociology and focuses on the study of technology, culture, and workplace organizations. Her most recent work examines the nature of computer-centered, high-tech industry. She is particularly interested in the how the workplace and employer-employee relations change when in a high-tech environment. At the core of her research is her interest in the social values attributed to technology and the power structures that arise within organizations due to the manipulation and use of those techno-values, in other words, techno-social capital. Andrea can be reached by e-mail at atapia@ist.psu.edu. 